\title{
PROCESSO DA CONSTITUIÇÃO DA FRONTEIRA E CULTURA ÉTNICA ENTRE A COMUNIDADE FULA E MANDINGA EM GUINÉ-BISSAU
}

\author{
Sambite Santos Cabi ${ }^{1}$ \\ Fernando José Martins ${ }^{2}$
}

\begin{abstract}
RESUMO: O presente artigo tem o objetivo de abordar os processos de constituição da fronteira na identidade cultural e tradicional guineense (Guiné-Bissau), especificamente das etnias Fula e Mandiga. A análise será desenvolvida a partir da convivência e da relação do autor com o conflito envolvendo o território e o processo de constituição étnica da identidade Fula e Mandiga. O trabalho consiste em uma discussão teórica sobre os conflitos territoriais envolvendo as duas etnias na procura de espaço e domínio no reino de Gabu. A metodologia utilizada baseia-se em levantamento bibliográfico a partir das principais referências sobre assunto, destacando autores como Docke (1999), Ratzel (1990), Silveira (2005) e Haesbaert (2004), os quais nos ajudam a compreender o conflito entre os dois povos na procura de dominação do território. O processo de constituição das sociedades fulas e mandingas no território da Guiné-Bissau começou com a chegada dos primeiros fulas no século XV (DJALO, 2012). Entende-se quea chegada de fulas no território de reino de Gabu deu início ao processo de constituição étnico fula e mandinga nas comunidades da atual Guiné-Bissau, apesar de os mandingas já terem habitado o território do reino de Gabu antes dos conflitos.
\end{abstract}

Palavras-chave: Fronteiras Étnicas; Identidade; Tradição.

\section{BORDER CONSTITUTION PROCESS AND ETHNIC CULTURE BETWEEN THE FULA AND MANDINGA COMMUNITY IN GUINEA-BISSAU}

\begin{abstract}
This article aims to approach the processes of constitution of the border in the Guinean-Guinean (Guinea-Bissau) cultural and traditional identity, specifically of the Fula and Mandiga ethnic groups. The analysis will be developed from the author's coexistence and relationship with the conflict involving the territory. and the process of ethnic constitution of the Fula and Mandiga identity. The work consists of a theoretical discussion about territorial conflicts involving the two ethnic groups in the search for space and dominion in the kingdom of Gabu. The methodology used is based on a bibliographic survey based on the main references on the subject, highlighting authors
\end{abstract}

\footnotetext{
${ }^{1}$ Bacharelado em Humanidades - Universidade de Integração Internacional da Lusofonia Afro-Brasileira - Unilab (2017), Especialização em Gestão Pública - Unilab (2018), licenciado em Sociologia em Unilab (2019) e atualmente estudante de pós-graduação de Sociedade, Cultura e Fronteira em Universidade Estadual do Oeste do Paraná (Unioeste - Foz de Iguaçu - 2019). E-mail: sasacaguine@ otmail.com

${ }^{2}$ Possui graduação em Pedagogia - Orientação Educacional pela Faculdade Estadual de Ciências e Letras de Campos Mourão (2000), especialização em Supervisão, Orientação e Gestão Escolar pela Faculdade de Ciências e Letras de Campo Mourão (2001), mestrado em Educação em Educação pela Universidade Federal do Paraná (2004) e doutorado em Educação pela Universidade Federal do Rio Grande do Sul (2009). Atualmente é professor Associado da Universidade Estadual do Oeste do Paraná - Foz do Iguaçu (2019). E-mail: fernandopedagogia2000@yahoo.com.br
}

Programas de Pós-Graduação em Ciências Sociais e Filosofia - UNIOESTE - Rua da Faculdade 645. Toledo - PR. CEP 85.903-000 Email: revistaalamedas@gmail.com 
such as Docke (1999), Ratzel (1990), Silveira (2005) and Haesbaert (2004), which help us to understand the conflict between the two peoples in the search for domination of the territory. The process of setting up Fula and Mandingo societies in Guinea-Bissau began with the arrival of the first Fula in the 15th century (DJALO, 2012). It is understood that the arrival of Fulas in the territory of the kingdom of Gabudeu started the process of ethnic constitution of Fula and Mandingans in the communities of present-day Guinea-Bissau, despite the fact that the Mandingas had already inhabited the territory of the Kingdom of Gabu before the conflicts.

Keywords: Ethnic Borders; Identity; Tradition.

\section{INTRODUÇÃO}

No presente artigo analisamos historicamente a trajetória dos grupos étnicos Fulas e Mandingas durante o conflito em busca de espaço territorial no século passado, bem como os processos de constituição de fronteiras entre Fulas e Mandingas e a influência social entre os dois grupos étnicos nos seus territórios. A análise busca reforçar o conhecimento sobre a importância do território na constituição da identidade étnica (tribo) no contexto do papel do casamento tradicional dentro da família tradicional da Guiné-Bissau. Objetiva-se fazer uma abordagem teórica sobre os conflitos entre as tribos em busca de espaço territorial. A metodologia utilizada para este artigo é a pesquisa bibliográfica, realizada através de leituras de livros, monografias, teses e artigos, considerando sobretudo as pesquisas relacionadas à realidade guineense presentes em bancos de dados nacionais e internacionais de livre acesso.

Em um primeiro momento, busca-se articular o conflito histórico entre Fulas e Mandingas no antigo território que pertencia, na época, ao reino de Gabu. Em um segundo momento, desenvolve-se um debate sobre o processo da constituição dos grupos étnicos Fulas e Mandigas no território guineense. E, finalmente, trazemos as nossas considerações finais.

\section{CONFLITOTERRITORIALENTRE ETNIAS (TRIBOS) FULAS E} MANDINGAS 
Historicamente, no século XVIII, a atual Guiné-Bissau fazia parte do reino de Gabu, sob domínio do império de Mali. Nesta época, era grande a busca pela conquista de espaços entre grandes impérios na África, o que ocasionava várias guerras,que tinham o objetivo de ganhar mais territórios, além de aumentar o poder econômico e político. Consequentemente, "se analisarmos mais adiante as tradições que se reportam a tal expansão para o Oeste, percebemos que talvez ela tenha sido a consequência de certas características sociais e econômicas da sociedade" (OGOT, 2010, p. 442).

$\mathrm{Na}$ busca por espaço, os guerreiros passaram a se agrupar em direção ao Oeste com o intuito de constituir os seus Estados, sendo que "grande parte destes grupos migrantes era também animada pelo desejo de participar das trocas comerciais, cada vez mais numerosas na região da fronteira ocidental, e de ter parte na riqueza que estava aumentando (OGOT, 2010, p.442).

Portanto, dentro desta perspectiva, "os movimentos migratórios são igualmente percebidos pelas múltiplas trocas entre os diversos grupos étnicos e linguísticos, os quais conferiram espaço às novas misturas" (OGOT, 2010, p.442). No que diz respeito aos movimentos migratórios das populações na ocasião, estudiosos africanos afirmam que,

\footnotetext{
Em relação àquele dos séculos precedentes, o movimento dos povos que caracteriza os séculos XVII e XVIII afetou toda a zona costeira e subcosteira e exprimiu-se em fluxos migratórios em várias direções: eles não só foram orientados do Norte para o Sul ou do interior para a costa, mas também Sul-Norte, Leste-Oeste e Oeste-Leste. O setor indo da Libéria a Tano é foi o mais afetado. Segundo Warren L. d'Azevedo, tais movimentos de população foram, em grande parte, suscitados pelo desejo de controlar o tráfico de escravos que, por sua vez, provocou conflitos e, portanto, a formação de alianças militares e comerciais entre as etnias e no interior delas. Esta situação culminou no estabelecimento de estreitas ligações culturais entre diversos grupos étnicos da região (OGOT, 2010, p.448-449).
}

Apesar disso, o controle do grande tráfico negreiro pode ser visto não só como uma forma de acumulação de capital, bem como de ocupação de espaços de fronteiras que eram parte importante entre grupos guerreiros. Nesta senda, havia uma busca de variação espacial não só econômico, mas também territorial (espaço físico) entre grandes grupos étnicos no continente negro. Segundo Niane (1989), esta conjuntura induziu a invasão de Fulas e o fim do Reino Mandinga do Gabu em 1867. 
Assim sendo, "essas mudanças têm suas razões na expansão de grupos fulas do império Mandinga de Cabú e de Firdu. Essa expansão vai ter como consequência vários conflitos internos. Registrem-se as contendas entre fulas e mandingas e biafadas, envolvendo também os portugueses" (SEMEDO, 2010, p.63). O envolvimento dos portugueses na época tinha o objetivo de dividir os povos para melhor controlar a área da costa oeste da África, antes da divisão do continente entre potências européias na conferência de Berlim, entre novembro de 1884 e fevereiro de 1885, perante comando do Chanceler Alemão.

Segundo Semedo (2010, p. 63), "a queda dos impérios africanos vai coincidir com a ascensão do comércio de escravos na costa de África. Segue-se um período de conflito entre as potências, que vai ser solucionado pela Conferência de Berlim”. Vale recordar que as forças européias durante todo século da colonização mostraram que "na geografia, a ideia de fronteira estava diretamente vinculada aos processos de expansão territorial dos impérios da Europa e nas regiões de colonização em outros continentes" (CARDIN; ALBUQUERQUE, 2018, p.115).

Outro aspecto que se pode destacar nessa concepção da fronteira contemporânea é que "o conceito de fronteira trazido pelos colonizadores europeus não representava muita novidade para as sociedades africanas" (DOPCKE, 1999, p.78). Durante a invasão européia na África, o problema sobre fronteira passou a ser a principal causa de vários conflitos pós independência. Segundo Ratzel (1990), questões de delimitações de fronteira são um grande erro, porque esse assunto é pensado como "simples linhas ou divisórias, e não como instrumentos vivos no desenvolvimento dos fenômenos máximos cujo teatro é a Terra" (RATZEL, 1990, p. 95). Na verdade, quando se trata da problemática de fronteira na África, é importante levar em conta a realidade da sociedade africana, que é totalmente diferente da européia, tendo em vista que a colonização tem contribuído para grande transformação social na África. Isso nos leva a afirmar que "a peculiaridade da fronteira parece estar no fato de que ela, ao vincular-se à noção de limite, acaba por criar condições que fazem com que esse fenômeno seja um jogo constante entre vida e morte, abarcando também a possibilidade de lidar com aquilo que é potencialmente agregador [...]" (SILVEIRA, 2005, p.19). Concordamos com a ideia de Silva (2005), porque essa perspectiva de agregação possibilitou, depois 
de grande conflito histórico, a integração entre Fulas e Mandigas nas regiões de Bafatá e Gabu, no leste da Guiné-Bissau.

Historicamente, as regiões de Bafatá e Gabu, para além de serem zonas de fácil acesso a países vizinhos, como Senegal e Guiné-Conakry, são regiões muito conhecidas pelo comércio, principalmente a região de Gabu, que é considerada como uma cidade de referência no comércio. Portanto, entendemos que estas duas regiões têm grande implicação nos dois grupos étnicos, porque Fulas e Mandingas são conhecidos como povos comerciantes e, atualmente, são povos que dominam a atividade comercial na Guiné-Bissau. A partir dos elementos indicados acima, podemos apontar a importância do comércio como elemento central que incide na delimitação do território, apesar do papel e da importância das duas regiões durante conflito entre Fulas e Mandingas no antigo reino de Gabu, era visto como questão de dominação e não como influência do comércio que esta região tem na história; assim "o território é funcional a começar pelo território como recurso, seja como proteção ou abrigo ("lar" para o nosso repouso)" (HAESBAERT, 2004, p. 3). Diante disso, para estas etnias (tribos), o território passou a ser espaço de sociabilidade por causa de semelhança cultural. Hoje, politicamente, "o território substitui assim outras formas de cumprir a função de dominação (laços pessoais, comunitários, tribais, etc.)" (PIRES, 2016, p. 28). Nessa dinâmica, o espaço que constitui as regiões de Gabu e Bafatá é caracterizado por um sistema de organização social e econômica, com elementos da cultura Islâmica. Essas são as principais semelhanças entre Fulas e Mandingas.

\section{OS PROCESSOS DA CONSTITUIÇÃO DAS FRONTEIRAS ÉTNICOSENTRE FULA E MANDINGA NA GUINÉ-BISSAU}

Podemos olhar a questão de processo de constituição dos grupos étnicos independente de local (lugar) especifico, como o território ocupado pelo grupo de pessoas ou etnias de forma livre, isso "poder-se-ia dizer que o território-região é uma categoria administrativa de grupos étnicos que aponta para a de modelos alternativos de vida e sociedade" (ESCOBAR, 2005, p.78). Na atualmente, "pode distinguir-se na realidade da Guiné-Bissau três grupos sociais. Um indígena (africanos animistas), outro de influência árabe (islamizados pelos árabes Almorá vidas desde os séculos XII-XIII) e 
outro de influência européia (cristianizados)" (PINTO, 2009, p.3). Entre os islamizados, os grupos étnicos Fulas e Mandigas receberam grandes influências árabes; contudo, depois da chegada dos europeus, alguns aceitaram adotar a civilização dos dominantes.

Nessa andança, almeja-se abordar a estratégia dos dois grupos étnicos a partir de um olhar histórico de constituição das suas fronteiras, que foi marcado desde o século XVIII. Assim sendo,

Pode-se dizer que a história de relacionamento entre estes povos de um lado e os Fulas e Mandingas do outro e, também estes entre si, modificaram radicalmente o panorama político na região. Entre estes dois, aquele que maior influência exerceu sobre os restantes foram os mandingas, a ponto de muitos estudiosos falarem do fenômeno de mandinguização para resumir esta forte influência cultural e política, que foi extensiva a uma parte considerável da região, abarcando muitas etnias que pagavam tributo ao reino mandinga de Kaabu. Estima-se que durante o século XVIII deviam existir entre setenta a oitenta diferentes reis e chefes tradicionais (leading chiefs) que reinavam simultaneamente no que outrora correspondia ao actual território da GuinéBissau, mas todos estavam submetidos, de uma maneira ou doutra, ao reino mandinga (CARDOSO, 2017, p.12).

O conflito histórico entre Fulas e Mandingas foi marcante no processo de constituição das suas comunidades na Guiné-Bissau. Nesse caso, o desempenho de Fulas na organização das suas comunidades é um princípio muito fundamental se observamos pela sua trajetória histórica desde séculos passados.

Para Djaló (2012), os primeiros Fulas chegaram ao atual território da GuinéBissau em meados do século XV, os primeiros grupos eram formados por pastores que desejavam se hospedar pacificamente no Gabu (Kaabu). Além disso, este autor cita René Pélissier, o qual afirma que “os fulas constituem o 'elemento perturbador' da história guineense na segunda metade do século XIX. Este grupo pertence à grande família dos povos que, através de imigrações, invasões e sucessivas mestiçagem alterou permanentemente a história da África Ocidental (DJALO, 2012, p.71).

Entre comunidades fulas, "apenas na Guiné-Bissau distingue-se os Fulas-Fulas (Fulas do Fouta-Djallon), que tinha distribuído o reino de mandinga do Gabú, libertando assim os seus primos, os Fulacundas ou Fulas-Forros, da dominação Mandinga" (DJALO, 2012, p. 71).

Durante todo esse processo histórico da etnia, com a derrota, os Fulas procuraram assumir definitivamente o seu domínio territorial até hoje na zona leste da 
Guiné-Bissau, com uma forte organização social. Entretanto, também podemos encontrar a forte presença dos Mandingas. "A organização social dos Fulas repousava inicialmente sobre os quatros grupos clãs principais, cujos membros se identificam por um determinado nome da família. [...] Igualmente, os do Clã Djal-Djaló, usam o nome de Diallo, Djaló ou Jaló, os do Clã Ururó, o nome de Baldé os do Clã Daédió, o nome do Bari e os Clã péédjo, o nome de Sóh" (DJALÓ, 2012, p.72).

Nesse ponto de vista, socialmente, os Fulas são plenamente dominantes, não por causa de sua organização social, mas, sim, pela quantidade de pessoas que constituíram em relação aos Mandingas. Mas é bom ressaltar que os Fulas e Mandigas continuaram a viver maioritariamente no leste da Guiné-Bissau e "a manutenção das fronteiras baseiase no reconhecimento e nas validações das distinções étnicas no decurso das interações sociais" (POUTIGNAT, 1998, p.158). Por conseguinte, nessa perspectiva, "a fronteira só deixa de existir quando o conflito desaparece, quando os tempos fundem, quando a alteridade original e mortal dá lugar à alteridade política, quando o outro se torna a parte antagônica de nós” (MARTINS, 1996, p.27).

Portanto, "no decorrer do tempo as fronteiras étnicas podem manter-se, reforçarse, apagar-se ou desaparecer" (POUTIGNAT, 1998, p.154). Assim sendo, na perspectiva da composição social, Oliveira (1978) assegura que

\footnotetext{
Ao nível da estrutura social, entretanto, admite-se que os grupos portadores de identidade minoritária possam ser "simples" ou " complexos", possuam formas tribais de organização ou sejam segmentos das sociedades nacionais em que se inserem, reproduzindo-as de certo modo no plano de sua própria organização o que lhes confere uma inevitável homologia estrutural com a sociedade envolvente (OLIVEIRA,1978, p. 248-249).
}

Apesar dos conflitos históricos entre os Fulas e Mandingas, cada um mantêm-se com sua forma de estrutura social e política, sem que haja problema de conflito entre as partes por causa das suas diferenças da organização social. Tudo isso tem a ver com a própria "diversidade que é, sobretudo, diversidade de relações sociais marcadas por tempos históricos diversos e ao mesmo tempo, contemporâneo" (MARTINS, 1996, p. $30)$.

Por outro lado, historicamente, "essa diversidade se manifesta na originalidade e na pluralidade de identidades que caracterizam os grupos e as sociedades que compõem 
a humanidade" (UNESCO, 2001, p. 3). Nesse sentido, "fonte de intercâmbios, de inovação e de criatividade, a diversidade cultural é, para o gênero humano, tão necessária como a diversidade biológica para a natureza" (UNESCO, 2001, p. 3).

\begin{abstract}
A partir dessa visão entende-se a diversidade como uma variável dependente da cultura e como um conceito discutível e relativo, pois somente se origina a partir do momento em que há uma dicotomia entre pelo menos dois grupos, onde um se enxerga diferente do outro a partir de algumas dimensões (tais como, raça, gênero, etnia e nacionalidade), mas não pelas dimensões em si, mas pelo significado e valor cultural que elas atribuem ao grupo (PEREIRA; HANASHIRO, 2007, p.3).
\end{abstract}

Nessa definição, não se pode afirmar que entre grupos étnicos Fulas e Mandigas as diferenças nos valores culturais sejam atribuídos entre as partes. Contemporaneamente, o debate sobre a diversidade e cultura passa a ser sobre os termos ligados às ciências humanas e "a diversidade torna-se um termo cultural e político usado nos contextos de novos horizontes conceituais sobre as sociedades" (BAUER, 2016, p.6). Realmente, essa diversidade cultural é a principal característica da identidade do povo Fula e Mandinga, “assim, quando falamos em diversidade cultural entendemos que há distintas sociedades e culturas. Em diferentes tempos e espaços, os humanos adotam maneiras variadas de convivência, valorizando suas diferenças e criando formas de expressá-las em seu meio social” (CEDERJ, 2017, p.12).

De acordo com Bauer (2016), a cultura é um código de uso e de reconhecimento de valores e de ações, onde as atuações sociais são, ambos, um indicador, mas, além disso, um conjunto de controle de referências para a difusão. Acultura na África é vista como a única forma de manter a tradição, as identidades, as práticas religiosas e costumes tradicionais entre grupos étnicos e sua principal característica está nas suas diversidades. Hoje, a diversidade da cultura africana passa pela história de tráfico dos africanos pelo resto dos continentes. A cultura africana passa completamente a ser vista como cultura universal. Por exemplo, no Brasil, a cultura afrodescendente veste raízes africanas, como se pode ver "as religiões chamadas afro-brasileiras surgiram durante o processo de colonização do Brasil com a chegada dos escravos africanos" (SILVA, 2014, p.31). 


\begin{abstract}
A tradição e cultura dos africanos escravizados, deixaram marcas importantes para o desenvolvimento da identidade das manifestações culturais, artísticas e musicais da população brasileira podendo ser percebida, por exemplo, através dos instrumentos e ritmos utilizados e tocados até os dias atuais, porque o povo aprende e assimila as manifestações culturais de forma natural e transmite esse aprendizado nas mais variadas formas de expressão (FILHO, 2016, p.2).
\end{abstract}

Quanto à influência cultural, pode-se afirmar que países colonizados pelos portugueses tiveram grande espaço na construção da cultura afro-brasileira e a língua é outro ponto importante a ser observado. De acordo com Silva (2005, p. 11), "a cultura, portanto, estabelece normas básicas de comportamento, mas ela é regulada por um número finito de regras, permitindo diversas variações dentro de uma única cultura". Pode-se pegar o Brasil para melhor compreender o contexto dos Fulas e Mandingas, onde as regras são as principais normas que regem a cultura e as tradições desses grupos étnicos dentro das suas comunidades, através das tradições orais e religiosas que vieram da própria trajetória histórica do povo Fulas e Mandinga. Segundo Laraia (2001, p. 22), "a cultura é um processo acumulativo, resultante de toda a experiência histórica das gerações anteriores. Este processo limita ou estimula a ação criativa do indivíduo”.

Contemporaneamente, a cultura continua a ser a parte da história e da experiência dos Fulas e Mandingas em toda sua manifestação cultural,desse modo cultura "[...] configura-se como uma teia de significações, e na sociedade atual, este aspecto desdobra-se no momento em que surge uma hibridez de culturas caracterizada por uma mescla ou convivência de várias culturas" (PORTO, 2010, p.26).

Dessa maneira, a construção da identidade dos grupos étnicos continua a ser vivida na base da experiência. Para Diehl (2016, p. 65) "a cultura como texto da experiência somente se deixa compreender quando forem levados em conta os processos peculiares de modernização através das ideias de futuro que se tinha no passado contido na própria experiência do mundo da vida no qual está se torna uma referência para a constituição de sentido".

Segundo Diehl (2016), a cultura é a totalidade de atuações em modelos da experiência, integrando os aspetos relacionados a variedades e à diversidade do procedimento da vida nas afinidades sociais. Ainda mais à frente, Diehl (2016, p. 69) revela que a "cultura possui, finalmente, funções de significação no sentido de sua capacidade para (re)elaborar experiências contingências”. 
Buscou-se debater sobre a delimitação de fronteira na realidade africana, especificamente, na Guiné-Bissau, relacionando-a com a cultura no contexto africano, onde cultura e fronteira têm ligação. Hoje, a cultura e a fronteira são vistas como um espaço de modernização e de globalização, ainda na África com toda descentralização da cultura pelo mundo, a sociedade continua a ser radical na preservação cultural, não só parte das suas identidades também como forma de manter e respeitar as culturas tradicionais dos antepassados.

\section{CONSIDERAÇÕES FINAIS}

Historicamente, as etnias (tribos) Fulas e Mandigas tiveram uma luta em busca de dominação territorial do antigo império de Gabu desde o final do século XVIII, uma vida migratória marcada pelo conflito entre eles. As duas etnias têm uma ligação histórica e religiosa (Islâmica/Muçulmanos) e também uma união cultural tradicional, apesar de cada etnia ter a sua língua materna diferente da outra. Deste modo, independentemente das lutas pela dominação, a constituição dos Fulas e Mandigas sempre esteve ligada à pluralidade de identidade e sempre está presente, caracterizando as suas sociedades.Também, por outro lado, percebe-seque o conflito faz parte da constituição histórica dos dois povos. Hoje, é visível entender que a fronteira e cultura podem distanciar os Fulas e Mandingas; mas, ao mesmo tempo,cultura e fronteira ajuda na interação entre os dois povos.Os espaços locais da cultura sempre foram ricos em socialização entre estes grupos étnicos. Isso significa que o ponto de vista fronteiriço e cultural estendeu e permitiu, sobretudo no nosso século, o regresso das nossas identidades, da localização e de oportunidades, de modo que permite perceber a forma como fronteira e cultura estão ligadas à história dos grupos étnicos Fulas, Mandingas e entre outros. Quem sabe, a partir desse olhar, possamos explicar como a cultura e fronteira são vistas no contexto em que convivemos.

\section{REFERÊNCIAS BIBLIOGRÁFIAS}

ALMEIDA, C.; SANTANA, A. C. Identidade Quilombola e reconhecimento étnico: uma abordagem conceitual dos estudos culturais em comunicação. In: CONGRESSO DE CIÊNCIAS DA COMUNICAÇÃO NA REGIÃO SUL, 13., Chapecó, 2012. Anais 
[...]. Chapecó, 2012. Disponível em: http://www.intercom.org.br/papers/regionais/sul2012/resumos/R30-0292-1.pdf. Acesso em 28 jun. 2019.

BARROS, J. M. Cultura, mudança e transformação: a diversidade cultural e os desafios de desenvolvimento e inclusão. In: ENCONTRO DE ESTUDOS MULTIDISCIPLINARES EM CULTURA, 3., Salvador, 2007. Anais [...]. Salvador: UFBA, $2007 . \quad$ Disponível em: http://www.cult.ufba.br/enecult2007/JoseMarcioBarros.pdf. Acesso em: 28 jun. 2019.

BAUER, T. Cultura da diversidade: uma orientação teórica para a prática cultural de cooperação social. Revista Galáxia, n. 33, p. 05-19, 2016. Disponível em: http://www.scielo.br/pdf/gal/n33/1519-311X-gal-33-0005.pdf. Acesso em: 20 maio 2019.

BETTEGA, M. L. O casamento como manifestação de uma cultura: o caso de Nova Palmira. 2007. Dissertação (Mestrado em Cultura Regional) - Universidade de Caxias do Sul, 2007. Disponível em: https://repositorio.ucs.br/xmlui/bitstream/handle/11338/273/-

Dissertacao\%20Maria\%20Lucia\%20Bettega.pdf?sequence=1\&isAllowed=y. Acesso em: 15 jun. 2019.

BORGES, E. M. Estudo de caso em Gabú: será que o casamento explica a gravidez precoce das jovens islâmicas (fulas e mandingas)?. 2009. Dissertação (Mestrado em Estudos Étnicos Africanos) - Universidade Federal da Bahia, 2009. Disponível em: https://repositorio.ufba.br/ri/bitstream/ri/8838/1/dissertacao_ecyla.pdf. Acesso em: 18 jun. 2019.

BRASIL. Ministério da Educação. Secretaria de Educação Continuada, Alfabetização, Diversidade e Inclusão. História e cultura africana e afro-brasileira na educação infantil. Brasília: MEC/SECADI, 2014.

ENNER, M. A. Ocupação, renda e origem étnica: um estudo de caso. Caderno Pós Ciências Sociais - São Luís, v. 2, n. 3, jan./jun. 2005. Disponível em: http://www.periodicoseletronicos.ufma.br/index.php/rpcsoc/article/download/226/158.

Acesso em: 11 ago. 2019.

CARDIN, E. G.; ALBUQUERQUE, J. L. C. Fronteiras e Descolamentos. Revista Brasileira de Sociologia, v. 6, n. 12, 2018. Disponível em: http://www.sbsociologia.com.br/-rbsociologia/index.php/rbs/article/view/350/200.

Acesso em: 20 maio 2019.

CARDOSO, C. Formação da Elite Política na Guiné-Bissau. Centro de Estudos Africanos. [2017?]. Disponível em: https://core.ac.uk/download/pdf/38680294.pdf. Acesso em: 20 maio 2019. 
CARVALHO, M. A Construção das identidades no espaço escolar. Revista Reflexão e Ação, Santa Cruz do Sul, v. 20, n. 1, p. 209-227, 2012. Disponível em: https://online.unisc.br/seer/index.php/reflex/article/view/2161. Acesso em: 25 jun. 2019.

CEDERJ - CENTRO DE EDUCAÇÃO A DISTÂNCIA DO ESTADO DO RIO DE JANEIRO. Cultura, diversidade cultural e desigualdades sociais. Material didático de Sociologia, $\quad$ v. $1.2017 . \quad$ Disponível em: http://projetoseeduc.cecierj.edu.br/eja/recurso-multimidiaprofessor/sociologia/novaeja/m1u11/ch_mod01_vol1_unidade-11-ALUNO.pdf. Acesso em: 30 jun. 2019.

COSTA, M. M. O casamento. Revista Sol Nascente, 2012. Disponível em: http://docplayer.com.br/1584548-O-casamento-maria-manuela-da-costa.html. Acesso em: 20 maio 2019.

CUCHE, D. A noção de cultura nas ciências sociais. 2. ed. Bauru: EDUSC, 2002.

DIEHL, A. A. Max Weber: Ciência da Cultura e História. Revista de Teoria da História, v. 16, n. 2, $2016 . \quad$ Disponível em: https://www.revistas.ufg.br/teoria/article/view/44810. Acesso em: 28 maio 2019.

DJALO, T. O mestiço e o poder: identidade dominações e resistências na Guiné. Lisboa: Nova Veja, 2012.

DOPCKE, W. A vida longa das linhas retas: cinco mitos sobre as fronteiras na África Negra. Rev. Bras. Polít. Int., v. 42, n. 1, 1999. Disponível em: http://www.scielo.br/pdf/rbpi/v42n1/v42n1a04.pdf. Acesso em: 19 dez. 2019.

ESCOBAR, A. O lugar da natureza e a natureza do lugar: globalização ou pósdesenvolvimento? In: ESCOBAR, A. A colonialidade do saber: eurocentrismo e ciências sociais: Perspectivas latino-americanas. Buenos Aires: CLACSO, 2005. Disponível em: http://www.iea.usp.br/eventos/escobar-natureza. Acesso em: 29 jun. 2019.

FERNANDES, I. O lugar da identidade e das diferenças nas relações sociais. Textos $\boldsymbol{\&}$ Contextos, v. 5, n. 2, p. 1-12, 2006. Disponível em: http://www.redalyc.org/pdf/3215/321527159005.pdf. Acesso em: 13 maio 2019.

FILHO, V. J. S. Uma análise histórica das influências da cultura dos povos de matriz africana sobre a identidade musical brasileira. In: SIMPOSIO NACIONAL DE HISTORIA, 27., Natal, RN, 2016. Anais [...]. Natal, RN, 2016. Disponível em: http://www.snh2013.anpuh.org/-

resources/anais/27/1371166520_ARQUIVO_Artigo.Umaanalisehistoricadasinfluencias daculturadospovosdematrizafricanasobreaidentidademusicalbrasileira.pdf. Acesso em: 10 maio 2019. 
GAMA, J. Cultura e valor - Para uma Filosofia da Cultura [2000?]. Disponível em: https://www3.ufpe.br/ppgfilosofia/images/pdf/pf4e5_artigo5a0001.pdf. Acesso em: 30 jun. 2019.

GARRAFÃO, Y. V. M. Casamento tradicional na Guiné-Bissau: O k’mari na etnia Papel. Revista África e Africanidades, v. 11, n. 26, 2018. Disponível em: http://www.africaeafricanidades.com.br/documentos/0010260042018.pdf. Acesso em: 12 jul. 2019.

GOMES, N. L. Cultura negra e educação. Revista Brasileira de Educação, n. 23, 2003. Disponível em: http://www.scielo.br/pdf/rbedu/n23/n23a05.pdf. Acesso em: 01 jul. 2019.

HAESBAERT, R. Dos múltiplos territórios á multiterritorialidade. 2004. Disponível em http://www.ufrgs.br/petgea/Artigo/rh.pdf.Acesso em: 22 maio 2019.

HEMMINGS, J.; KHALIFA, S. Eu carrego o nome dos meus pais: Reflexões de jovens acerca da MGF e Casamentos Forçados . 2013. Disponível em: http://www.apf.pt/sites/default/files/media/2015/eu_carrego_o_nome_dos_meus_pais.p df. Acesso em: 25 jun. 2019.

LARA, C. B. Q. A Importância da memória para a construção da identidade: o caso da igreja Nossa Senhora Imaculada Conceição de Dourados/MS. In: ENCONTRO REGIONAL DE HISTÓRIA, 13., Coxim, MS, 2016. Anais [...]. Coxim, MS, 2016. Disponível em: http://www.encontro2016.ms.anpuh.org/resources/anais/47/1477593926_ARQUIVO_AIMPORTANCIADAMEMORIAPARAACONSTRUCAODAIDENTI DADE.pdf. Acesso em: 30 jun. 2019.

LARAIA, R. B. Cultura: uni conceito antropólogo. 14. ed. Rio de Janeiro: Jorge Zahar Ed., 2001. Disponível em: https://www.academia.edu/12002249/Roque_Laraia__Cultura_um_conceito_Antropol\%C3\%B3gico. Acesso em: 30 jun. 2019.

MARTINGO, C. Casamentos infantis, precoces, forçados e combinados - uma questão de direitos humanos e desenvolvimento. Portugal: PDFactor, 2017.

MARTINS, J. S. O tempo da fronteira. Retorno à controvérsia sobre o tempo histórico da frente de expansão e da frente pioneira. Tempo Social Rev. Social, v. 8, n. 1, p. 25 70, 1996. Disponível em http://www.scielo.br/scielo.php?pid=S010320701996000100025\&script=sci_abstract\&tlng=pt. Acesso em: 15 maio 2019.

MATEUS, M. R. M. Promoção dos direitos da mulher e da criança na Licenciatura em Educação de Infância da Faculdade de Ciências da Educação da Universidade Católica da Guiné Bissau. 2016. Dissertação (Mestrado em Gestão Escolar) Universidade Aberta, Portugal, 2016. Disponível em: https://repositorioaberto.uab.pt/bitstream/10400.2/6552/1/TMAGE_MReginaMateus.pdf. Acesso em: 30 jun. 2019. 
MORGADO, Ana Cristina. As múltiplas concepções da cultura: As múltiplas concepções da cultura. Revista Múltiplos Olhares, v. 4, n. 1, 2014. Disponível em: http://portaldeperiodicos.eci.ufmg.br/index.php/moci/article/view/2333. Acesso em: 28 jun. 2019.

NIANE, D. T. Histoire des Mandingues de l'Ouest. Paris: Karthala-Arsan, 1989.

OGOT, B. A. História geral da África: África do século XVI ao XVIII. Brasília: UNESCO, 2010. 1208 p.

OLIVEIRA, R. C. Identidade e estrutura social. São Paulo: Editora Pioneira, 1976.

PEREIRA, J. B. C.; HANASHIRO, D. M. M. A Gestão da Diversidade: uma Questão de Valorização ou de Dissolução das Diferenças? In: ENCONTRO DA ANPAD, 31. Rio de Janeiro, 2007. Anais [...]. Rio de Janeiro, 2007. Disponível em http://www.anpad.org.br/admin/pdf/EOR-B3178.pdf. Acesso em: 10 jun. 2019.

PINTO, P. Tradição e modernidade na Guiné-Bissau: uma perspectiva interpretativa do subdesenvolvimento. 2009. Dissertação (Mestrado em Estudos Africanos) Universidade do Porto, Portugal, 2009. Disponível em: https://repositorioaberto.up.pt/bitstream/10216/23-

213/2/tesemestpaulapinto000093779.pdf. Acesso em: 29 jun. 2019.

PIRES, E. L. Território, Governança e Desenvolvimento. Caderno Prudentino de Geografia, Presidente Prudente, n.38, v.2, p.24-49, ago./dez. 2016. Disponível em: http://revista.fct.unesp.br/index.php/cpg/article/download/5500/4099. Acesso em: 29 jun. 2019.

PORTO, C. M. Impacto da internet na difusão da cultura científica brasileira: as transformações nos veículos e processos de disseminação e divulgação científica. 2010. Tese (Doutorado em Cultura e Sociedade) - Universidade Federal da Bahia, 2010. Disponível em: https://repositorio.ufba.br/ri/bitstream/ri/9038/1/Cristiane\%20de\%20Magalh\%C3\%A3e s\%20Porto.pdf. Acesso em: 30 jun. 2019.

POUTIGNAT, P. Teoria de etnicidade: Seguidos de Grupos étnicos e as suas fronteiras de Fredrik Barth. São Paulo: UNESP, 1998.

RATZEL, F. Geografia do homem (antropogeografia). In: MORAES, A. C. R. (Org). São Paulo: Ática, 1990.

ROQUE, S. Um retrato da violência contra mulheres na Guiné-Bissau. 2011. Disponível em: https://www.academia.edu/22053432/Um_retrato_da_viol\%C3\%AAncia_contra_mulheres_na_Guin\%C3\%A9-Bissau. Acesso em: 25 jun. 2019. 
SABONTE, F. W. Construção do Estado - Nação Angolana: relações inter-étnicas, Nhaneka-Humbe na guerra civil. 2010. Dissertação (Mestrado em Antropologia) Universidade Federal do Pernambuco, 2010. Disponível em: https://repositorio.ufpe.br/bitstream/123456789/1055/1/arquivo736_1.pdf. Acesso em: 29 jun. 2019.

SEMEDO, M. O. C. S. As Mandjuandadi - Cantigas de Mulher na Guiné-Bissau: da tradição oral à literatura. 2010. 452 p. Tese (Doutorado em Literaturas de Língua Portuguesa) - Pontifícia Universidade Católica de Minas Gerais, 2010.

SILVA, A. F. R. Correspondentes Internacionais: um diálogo entre culturas. 2005. Trabalho de Conclusão de Curso (Graduação em Comunicação Social) - Universidade Federal de Juiz de Fora, 2005. Disponível em: http://docplayer.com.br/14779225Universidade-federal-de-juiz-de-fora-anna-flavia-rocha-e-silva-correspondentesinternacionais-um-dialogo-entre-culturas.html. Acesso em: 30 jun. 2019.

SILVA, J. D. B. S. Casa de Caridade Caboclo Batuara: Umbanda e espaço público. 2017. Trabalho de Conclusão de Curso (Especialização em Gestão Cultural) Universidade de São Paulo, 2017. Disponível em: https://paineira.usp.br/celacc/sites/default/files/media/tcc/artigo_final_primeira_versao_28_04_2017-revisado-.pdf. Acesso em: 29 jun. 2019.

SILVA, H. K. A cultura afro como norteadora da cultura brasileira. Perspectiva, v. 38, n. 144, p. 25-35, 2014. Disponível em: http://www.uricer.edu.br/site/pdfs/perspectiva/144_449.pdf. Acesso em: 13 maio 2019.

SILVA, L. P. Os desafios da escola pública paranaense na perspectiva professor pde. o resgate e a valorização da cultura e história afro brasileira. Cadernos PDE, v. 1, 2016. Disponível em: http://www.diaadiaeducacao.pr.gov.br/portals/cadernospde/pdebusca/producoes_pde/2016/2016_artigo_port_uenp_lucilenepereiradasilva.pdf. Acesso em: 29 jun. 2019.

SILVEIRA, F. L. A. As complexidades da noção de fronteira, algumas reflexões. Caderno Pós Ciências Sociais - São Luís, v. 2, n. 3, jan./jun. 2005. Disponível em: http://www.periodicoseletronicos.ufma.br/index.php/rpcsoc/article/download/223/155. Acesso em: 29 jun. 2019.

SIMÕES, M. L. N. Identidade cultural e expressões regionais: estudos sobre literatura, cultura e turismo. Ilhéus: Editus, 2006. Disponível em: http://www.uesc.br/editora-/livrosdigitais2/identidade_cultural.pdf. Acesso em: 28 jun. 2019.

TEIXEIRA, R. J. D. Cabo Verde e Guiné-Bissau: as relações entre a sociedade civil e estado. Recife: Editora da UFPE, 2015. 
TENSÕES MUNDIAIS: Revista do Observatório das Nacionalidades, Fortaleza, v. 7, n. 13, 2011. Edição Temática: África. Disponível em: https://revistas.uece.br/index.php/tensoesmundiais/issue/view/68. Acesso em: 25 jun. 2019.

UNESCO - ORGANIZAÇÃO DAS NAÇÕES UNIDAS PARA A EDUCAÇÃO, A CIÊNCIA E A CULTURA. Declaração Universal sobre a Diversidade Cultural. 2001. Disponível em: http://www.unesco.org/new/fileadmin/MULTIMEDIA/HQ/CLT/diversity/pdf/declaration_cultural_diversity_pt.pdf. Acesso em: 29 jun. 2019. 